\title{
Postoperative Analgesic Efficiency of Quadratus Lumborum Block lii Versus Peritubal Local Infiltration in Patients Undergoing Percutaneous Nephrolithotomy Operation: A Randomized Controlled Trial
}

Simon Halim Armanious ( $\sim$ Simondr106@gmail.com )

Department of Anesthesia, Faculty of Medicine, Ain shams university, Cairo, Egypt. https://orcid.org/0000-0003-0997-8147

\section{Tamer Nabil Abdelrahman}

Department of Anesthesia, Faculty of Medicine, Ain shams university, Cairo, Egypt.

Gamal Adel Abd el Hameed

Department of Anesthesia, Faculty of Medicine, Ain shams university, Cairo, Egypt.

Joseph M. Botros

Department of Anesthesia, Faculty of Medicine, El Fayoum university, Egypt

\section{Research article}

Keywords: Quadratus lumborum block, Peritubal infiltration, Percutaneous nephrolithotomy, Bupivacaine, postoperative pain

Posted Date: September 30th, 2020

DOl: https://doi.org/10.21203/rs.3.rs-78028/v1

License: (c) (1) This work is licensed under a Creative Commons Attribution 4.0 International License. Read Full License 


\section{Abstract}

\section{Background:}

The postoperative pain after percutaneous nephrolithotomy (PCNL) can be managed by many peripheral blocks techniques (e.g., paravertebral and quadrates lumborum block), and local anesthesia infiltration. Therefore, this prospective study was conducted to evaluate the effect of quadratus lumborum type III versus peritubal local infiltrating on postoperative analgesia for patients undergoing PCNL.

\section{Methods:}

Eligible subjects after exclusion of COVID-19 patients, with renal stones less than $2 \mathrm{~cm}$ undergoing PCNL surgery under general anesthesia. Eighty patients were randomly allocated to 2 equal groups. In the Quadratus group, participant received $20 \mathrm{~mL}$ of bupivacaine $0.25 \%$ in the fascial plane between the quadratus lumborum and Psoas muscle; and in the peritubal group, patients received $10 \mathrm{~mL}$ of bupivacaine $0.25 \%$ around the nephrostomy tube at 6 and 12 o'clock positions (total $20 \mathrm{~mL}$ ). The quadratus lumborum block and peritubal infiltration were performed by the primary investigator and the urologist, respectively. All patients received standard postoperative analgesia (paracetamol, ketorolac, and morphine via patient-controlled analgesia. Both patients and Data collecting staff were blinded to study group. Primary outcome was the visual analogue score at rest and on coughing or movement at 2 , $4,6,12$, and 24 hours. Secondary outcomes were 24 hours total morphine consumption, $1^{\text {st }}$ use of morphine pump.

\section{Results:}

Data were analyzed from 78 patients (39 patients in each group). The mean resting VAS score in quadratus group at 6 and 12 hours was (3), while the mean VAS in peritubal group was (4) and (5.5) at 6 and 12 hours, respectively. Dynamic VAS score in peritubal group at 6 hours was (mean 6) with $p<0.0001$ when compared to resting value. The 24 hours morphine consumption was $8-11 \mathrm{mg}$ and $17-20 \mathrm{mg}$, in quadratus and peritubal group, respectively (the difference in mean of 9 at the $95 \%$ confidence interval; $p<0.0001$ ). patients start to use morphine pump after $66.6 \mathrm{~min}$ and $72.1 \mathrm{~min}$ in group peritubal and quadratus, respectively.

\section{Conclusion:}

Quadratus Lumborum block was more effective than Peritubal LA infiltration regarding postoperative VAS score both at rest and during movement with lower postoperative morphine consumption and more satisfaction in patients undergoing PCNL surgery.

Trial registration: This prospective randomized trial was registered at Clinical Trials.gov in December, 2019. https://clinicaltrials.gov/ct2/show/NCT04215705.

\section{Background}


The first patient to undergo percutaneous nephrolithotomy (PCNL) for treatment of kidney stones was in 1976. Since then, this technique has had constant evolution, which increases its success rate. Open nephrolithotomy has been reduced to very minimal rates, and PCNL has become the $1^{\text {st }}$ choice of treatment for stag horns and other large renal stones (>2 cm in maximum diameter)[1]. However, like any other invasive procedure, it has its own complications, such as injury to related organs, hemorrhage and postoperative pain[2].

Surgical stress is accompanied by pain, immune- dysfunction, nausea, vomiting, ileus, increased cardiac demands, sleep disturbance and fatigue. Postoperative pain can cause prolonged length of stay in hospitals and increased recovery period. However, despite an explosion in our knowledge of the pathophysiology of acute pain, the development of new analgesics, methods of drug delivery, and implementation of pain reducing minimally invasive surgical techniques, acute postoperative pain management remains a huge challenge for operating team[3].

Many regional anaesthesia techniques has been studied for controlling PCNL postoperative pain. Epidural anesthesia has an advantage over general anesthesia in providing postoperative good analgesia although it delays patient ambulation and interfere with anticoagulant regimen[4]. Blind (anatomical) lumber plexus block overcome those disadvantages but it has a high failure rate. In the era of ultrasound (US), several nerve block has been used successfully with an accurate needle position, the most commonly tried was subcostal transversus abdominal plane (TAP) block, thoracic paravertebral block[5], erector spine block[6], US-guided intercostal nerve block (ICNB) performed at the $11^{\text {th }}$ and $12^{\text {th }}$ intercostal spaces[7] and quadratus Lumborum block[8].

Ultrasound guided Quadratus Lumborum block was first described by Blanco for controlling postoperative pain following abdominal surgery as a posterior approach to TAP block by injection of local anesthetic drug into the anterolateral margin of the Quadratus Lumborum muscle[9]. Furthermore, QL block type III as described by Børglum et al. was a transmuscular block where the local anesthetic is injected anteriorly between the psoas major muscle and the QL muscle. He also defined this block by using the shamrock sign to achieve segmental sensory and visceral block from T4 to L1. Quadratus Lumborum block III was considered to be an effective method for reducing the postoperative pain score and analgesic consumption[8].

It is known that local anesthetic (LA) deposition at the surgical site can suppress the local inflammatory response by directly inhibiting some phases of inflammation. Peritubal LA infiltration around the nephrostomy tube under fluoroscopic guidance is one of the modalities that was developed to overcome the postoperative pain of PCNL, and it was proven to be effective in postoperative analgesia and decreasing the need for both oral and intravenous (IV) analgesics [10].

This study was designed to compare ipsilateral Quadratus Lumborum block III to Peritubal local anesthetic infiltration for analgesia after PCNL surgery performed under general anesthesia (GA). We 
hypothesized that QL block would decrease postoperative pain measured by the Visual Analogue Scale (VAS) during the 36 hours postoperative.

\section{Methods}

This prospective, randomized study was conducted at Ain Shams University Hospital from December 2019 to July 2020. After approval of the Research Ethics Committee of Ain Shams University in December 2019, the study was registered at https://clinicaltrials.gov/ct2/show/NCT04215705. As the study was conducted during the COVID-19 pandemic, patients were screened before surgery by complete blood picture (CBC) for lymphopenia, Ct Chest for ground glass appearance, and PCR for viral antigen. COVID-19 patients were postponed and excluded from the study. Eighty adult patients aged 21-60 years, both American Society of Anesthesia (ASA) physical status I and II, scheduled for PCNL surgery were invited to enroll in this study.

Preoperative investigations for all patients included routine clinical examinations and laboratory investigations $\mathrm{CBC}$, prothrombin time (PT) and partial thromboplastin time (PTT), INR and ECG. Patients with bleeding disorders, allergies to local anesthetics, psychiatric patients, and those who refused to share in the study were excluded. Patients were reviewed by an anesthesiologist on the same day of surgery for any medical history to ensure fasting for at least 6 hours. The anesthesia plan and VAS score were discussed with the patient, and then they signed a formal consent form.

All patients received general anesthesia, standard monitoring include ECG, NIBP, $\mathrm{ETCO}_{2}, \mathrm{SPO}_{2}$ were applied, General anesthesia was induced with Propfol $(2 \mathrm{mg} / \mathrm{kg})$, fentanyl $(1 \mathrm{ug} / \mathrm{kg})$ Atracurium $(0.5 \mathrm{mg} / \mathrm{kg})$ then intubation was done with endotracheal tube, ventilation was controlled mechanically with tidal volume (6-8 ml/kg), $\mathrm{FiOQ}(0.6)$, rate of ventilation was adjusted to maintain end tidal $\mathrm{CO}_{2}$ in range of $35-45 \mathrm{~mm} \mathrm{Hg}$. Pantoprazole (40 mg) IV infusion and Granisetron (1 mg) slowly IV were given. Patients were turned to prone position and GA was maintained with isoflurane $2 \mathrm{MAC} \%$ and atracurium $0.1 \mathrm{mg} / \mathrm{kg}$ every 20 minutes.

At the end of the surgery, patients were randomly divided into two equal groups using computer generated table, placing them in a sealed envelope and then opening the envelope in the OR. Group Q, received Quadratus Lumborum Block III, Group P received Peritubal Local Infiltration. In Group (Q) patients were placed in the semilateral position so that the related kidney was in an upside position for the Quadratus Lumborum block which was performed by the primary investigator. After cleaning the surgical field with Povidone lodine Solution A broadband (5-2 MHz) curved array transducer (sonosite MTurbo ${ }^{\circledR}$ ) was used, and the probe was positioned at the level of the anterosuperior iliac spine and moved upward until the three muscles of the abdominal wall were defined clearly. The hook sign was identified by visualizing the posterior border of the external oblique muscle, leaving below the internal oblique muscle, and over the Quadratus Lumborum muscle. A hyperechoic line appears by tilting the probe down this line represents the intermediate layer of thoracolumber fascia. A 21-gauge 4-inch Stimuplex A needle; B. Braun Medical Inc., Melsungen, Germany) was introduced in plane from anterior to posterior by 
hydrodissection at the fascial plane between the QL and Psoas muscle with $20 \mathrm{ml}$ of $0.25 \%$ bupivacaine on in the side of PCNL.[11]

In group (L), while the patient was still in the prone position, a spinal needle 22-gauge 2-inch Stimuplex A needle; B. Braun Medical Inc was inserted along the nephrostomy tube by the urologist under fluoroscopy in the 6 and 12 o'clock positions, and the renal capsule was contacted. A total of $20 \mathrm{ml}$ bupivacaine $0.25 \%$ was infiltrated along the renal capsule, muscle, subcutaneous tissue , and the skin as described by Parikh et al.[12]. In both, groups patients were turned to the supine position, and recovery from GA was performed with $2.5 \mathrm{mg}$ neostigmine and $1 \mathrm{mg}$ atropine to antagonize the action of the muscle relaxant. Extubation was performed after fulfillment of the needed criteria, and the patient was moved to the postanesthetic care unit (PACU).

The postoperative analgesic strategy included 1-gram paracetamol given before extubation, which was repeated every six hours postoperatively. Additionally, patients were given IV ketorolac $10 \mathrm{mg}$ every 8 hours starting immediately after surgery. Patients in both groups were connected to a PCA machine containing morphine with a bolus dose of $1 \mathrm{mg}$ boluses, lockout interval $6 \mathrm{~min}$ with no basal rate, and maximum $100 \mathrm{mg} / 24 \mathrm{~h}$. Patient was instructed to use PCA for VAS $>4$.

\section{Measured parameters}

Postoperative pain was assessed as the primary outcome both at rest and during movement or cough (dynamic) by an independent observer who was blinded to the procedure to avoid detection biases. The Visual analog scale (VAS) was used with a scale from 0 to 10, where 0 means no pain and 10 means unbearable pain, and it was measured at $1,2,4,6,12$, and 24 hours postoperative. Other variables were recorded as a secondary outcome, such as total morphine consumption during the first 24 hours, first use of PCA, occurrence of complications such as nausea, vomiting or pruritus and patient satisfaction score.

\section{Statistical Analysis}

The collected data were organized, tabulated and statistically analyzed using SPSS software statistical computer package version 22 (SPSS Inc, USA). The Shapiro-Wilk test was used as test of normality. Numerical variables such as age, weight, height, BMl, surgery duration, stone size and first time to request analgesics were normally distributed and are described as the mean \pm standard deviation (SD). An independent t-test was used to compare the mean values of the two groups. Other variables were not normally distributed and were presented as median and interquartile range (IQR); Mann-Whitney U test was used as a test of significance. Linear mixed models were used to account for repeated measures of VAS scores. A fixed effect model was used for the group, and a random effect model was used to adjust for repeated measures over time. The time-to-event variables were evaluated using the Kaplan-Meier method, and the logrank test was used to compare the groups. Qualitative data are presented as numbers and percentages, and the chi-squared test was used to determine significance. A two-sided P-value of $<0.05$ was considered statistically significant. $P<0.01$ was considered significant when multiple comparisons were performed for pain scores at rest and movement 
Previous studies detected a $40 \%$ difference in VAS score between the study groups, which is the primary outcome in our study[10,11], G* power computer program version 3.1.9.2 was used to calculate the sample size required with $80 \%$ power, an alpha error of 0.05 and allocation ratio of 1.[13] A sample size of 37 patients was calculated per group. To compensate for drop outs the sample size was increased to 40 patients in each group.

\section{Results}

Data analysis using modified intension, as only participants who received all the study protocols, were included in the final data analysis. Although eighty patents were randomized into two groups, data collected from 39 patients in each group, and two patients were excluded from final analysis (one in each group): one patient in the $\mathrm{Q}$ group faced difficulty with the sonographic demonstration of quadratus muscle; in the Peritubal group, one patient declined to continue the study despite receiving the LA (Figure 1).

The baseline and operative characteristics were clinically nonsignificance between the two groups (Table 1), and the mean VAS score at rest (Figure 2) was lower in the Quadratus group at any point during the study time especially at 6 and 12 hours. At 6 hours postoperative the mean VAS score was 3 in the Quadratus group, while it was 4 in the Peritubal group with $P$ value $<0.0001$. also, at 12 hours VAS score was 3 in group Q and 5.5 in group $P$ which was considered to be significant. No significant difference between both groups till 4 hours postoperatively with mean VAS score after 2 hours was 2.9 in group Q and 4 in group P, as shown in Box plots figure. Dynamic VAS score (Figure 3) (coughing or movement) was clinically significantly higher among patients of Peritubal group at 6 hours VAS 5-6 (mean 6), while it was 4-5 (mean 4) at rest. In group Q dynamic VAS score at 6 hours was 4 while it was 3 at rest with P value 0.02 which was considered clinically non-significant.

The 24 hour cumulative morphine consumption (Table 2) was significantly higher in the Peritubal group (17-20 $\mathrm{mg}$ versus $8-11 \mathrm{mg}$ ) than in the quadratus group, with an estimated treatment effect of 7-10 and a mean difference of 9 at the $95 \%$ confidence interval. Patients in the Peritubal group started to use PCA after a mean of 66.6 min versus $72.1 \mathrm{~min}$ in the Quadratus group, which was earlier by $5.586 \mathrm{~min}$, as explained by the Kaplan-Meier method, to be significant (Figure 4); two patients in the Quadratus group did not use PCA.

No patients in the 2 groups were unsatisfied with the analgesia plane with a mean score range of 2-4, but patients in the Quadratus group were statistically more satisfied ( $p$-value 0.006$)$. The incidence of postoperative complication nausea, vomiting and pruritus was low and statistically nonsignificant in the 2 groups (Table 3 ).

\section{Discussion}


This randomized controlled double blind study, demonstrated that there was a significant difference in VAS score at 6 and 12 hours postoperatively in patients undergoing PCNL surgery for renal stone extraction under GA. Patients received ipsilateral peritubal infiltration or quadratus lumborum block. This difference was in favor of the Quadratus group and became more significant with the patient's movement. The time to first rescue morphine analgesia and 24 hours' total morphine consumption were significantly lower in the Quadratus group. The patient's satisfaction and postoperative incidence of side effects ( $N \& V$ and pruritus) were insignificant between the two groups.

Since holmium:yttrium-aluminium-garnet(YAG) laser introduction in 1990, the concept of day case PCNL has been risen [14], YAG laser and pneumatic lithotripsy improve success rate of PCNL and lower postoperative bleeding with subsequent hemoglobin drop[15]. Postoperative pain delay patient ambulation, so using local infiltration or peripheral nerve block techniques have an opioid sparing effect, shorten recovery and improves patient satisfaction. Ultrasound guided QL block has been described by Blanco as posterior extension of TAP Block to provide sensory block from T4-L2[16]; later, it was used effectively by Sindwani et al.[17]; to provide post laparoscopic nephrectomy. Peritubal or subcutaneous infiltration of the LA along the nephrostomy tube was used effectively as part of the PCNL postoperative analgesic strategy[10, 18].

In our study, VAS score was significantly lower in group Q than group P specially at 6 to 12 hours, which is the peak time for nerve block techniques, previous trial [19] compared transversus abdominal plane (TAP) block versus local infiltration in parturient undergoing caesarean section and found that block is superior to local infiltration after 6 hours. Postoperative VAS score was insignificant between both groups till 4 hours postoperative, this can be explained by how the Peritubal infiltration works. The local infiltration extends from the renal capsule to the skin, so it controls the parietal pain,[20]. Then it escapes to circulation giving a superior analgesic effect to Quadratus Lumborum block.

A previous study done by Ertuğrul Kılıç and Ersan Bulut,[21] they studied effect of QL block III on postoperative pain after PCNL surgery, their mean standard of deviation of VAS was lower than ours at any time postoperatively, although they inject $0.2 \mathrm{~mL} \mathrm{~kg}^{-1}$ of 0.0125 isobaric bupivacaine while we inject 0.25 bupivacaine. This difference could be because their procedure was performed under spinal anesthesia that could enhance the analgesic effect of the regional block.

Patients of quadratus group showed no significance difference in VAS score measured at rest and during movement, while patients in Peritubal group showed a significant higher VAS score during movement and cough, this difference was more significant especially at 12 and 24 hours postoperative. Strichartz explained that LA in peripheral nerve block techniques (QL block III) act by a dual action, the first is blocking neuronal $\mathrm{Na}^{+}$channel prevent impulse propagation, second action LA can decrease local inflammatory reactions by inhibition of some inflammatory phases as neutrophil priming and blocking some neuronal pathways, that can be activated by G protein coupled receptors and Kinase c [22]. 
A lower dynamic VAS score was also found in Yayik et al[23]. They studied the effect thoracic paravertebral block versus Peritubal infiltration after PCNL surgery, and found a significant lower dynamic VAS score in paravertebral block patients, which is consistent with our study. Other study compared regional block techniques as paravertebral block versus local wound infiltration after mastectomy and also found that paravertebral block patients had a lower postoperative VAS score[24].

we used post-operative morphine as it is the most commonly used opioid for PCA in our institution, Kilic and Bulut[21] published a study investigating the postoperative analgesic effect of QL block after PCNL, they inject $0.2 \mathrm{mgkg}^{-1}$ of $0.125 \%$ isobaric bupivacaine, they 24 hours total morphine consumption was $10.22 \mathrm{mg}$, in our study lower 24 hours morphine consumption was $(9 \mathrm{mg})$, as we inject a higher bupivacaine concentration ( $0.25 \%$ ), also we applied a multimodal analgesic strategy (ketolac and Paracetamol), which was intended to lower opioid consumption for early patient discharge.

In our study QL block significantly lower 24hour morphine consumption than Peritubal infiltration (9mg versus $18 \mathrm{mg}$, respectively), which was in accordance with a previous meta-analysis done by Xu et al.[25], who studied QL versus other analgesic methods in parturient undergoing cesarean section and found significant reduction in 24hours morphine consumption in QL block group as the LA solution can disperse to both paravertebral space and thoracolumbar plane, which are rich sympathetic and pain receptor, thus alleviating both somatic and visceral pain[26].

Parikh et al[10]. studied the postoperative analgesic requirement after a Peritubal infiltration of $20 \mathrm{ml}$ bupivacaine versus ropivacaine, they found that the first rescue analgesia was after $7.91 \pm 1.96 \mathrm{hours}$, the earlier use of PCA in our study $66.6 \pm 23$ min may be due to easiest use of PCA (at the patient's hand) while the used tramadol intravenous also, we instruct our patients to use PCA starting from VAS $>3$, to improve patient satisfaction.

\section{Study Limitation}

This study had some limitations. First, the main limitation of the study was that both the QL block and the peritubal infiltration were performed while the patients were under GA, so no sensory testing could be applied to assess the exact dermatomal distribution of sensory block. We were guided by the sonographic view in the $\mathrm{Q}$ group and fluoroscopic image in peritubal grou344 $\mathrm{p}$ for accurate needle position. Second, the size of the applied nephrostomy tube at the end PCNL was different, which may affect postoperative pain characteristics and analgesic requirements[27].

\section{Conclusion}

QL block was more effective than Peritubal LA infiltration regarding postoperative VAS score both at rest and during movement with lower postoperative morphine consumption and more satisfaction in patients undergoing PCNL surgery. 


\section{Abbreviations}

PCNL: Percutaneous Nephrolithotomy

IV: intravenous

US: Ultrasound

ICNB: intercostal nerve block

QL: Quadratus Lumborum

TAP: transversus abdominis plane

GA: General anesthesia

CBC: Complete Blood picture

YAG: holmium:yttrium-aluminium-garnet

VAS: Visual Analogue scale

LA: Local Anesthetics

\section{Declarations}

\section{Ethics approval and consent to participate}

This prospective study was granted permission by the ethics committee of Ain Shams university on $25 / 11 / 2019$. All patients signed approval consent before enrollment in the study.

\section{Consent for publication}

All author and participant agree for online publication.

\section{Availability of data and materials}

The data are available at https://www.synapse.org/\#!Synapse:syn22028899/files/

Additionally, the data of this article are available from the corresponding author upon request. The email address of the corresponding author is simondr106@gmail.com; simon_dr_106@hotmail.com.

\section{Competing interests}

The authors declare that they have no competing interests.

\section{Funding}


This research was supported by the authors; and no funding institute or company.

\section{Acknowledgments}

Hany El Zahaby, the chairman of the department of Anesthesia and all nursing staff at Ain Shams University Hospitals.

\section{Authors' contributions}

$\mathrm{SH}$ and TN conceived the study and share in its design. JM under took data collection, data capturing and handling. SH coordinate data analysis with the assistance and review by JM. SH and GA drafted the manuscript. Both SH and JM read and approved the final manuscript

\section{References}

1. yelikar a, shah p, dholaria p, mehta a, amlani j, joshi v: Mp68-17 a Randomised Controlled Study Comparing Standard Tubeless Pcnl \& Tubeless Mini-Pcnl for Renal Stones Less Than $2 \mathrm{~cm}$. Journal of Urology 2018, 199(4S).

2. Knoll T, Daels F, Desai J, Hoznek A, Knudsen B, Montanari E, Scoffone C, Skolarikos A, Tozawa K: Percutaneous nephrolithotomy: technique. World journal of urology 2017, 35(9):1361-1368.

3. Kehlet H: Postoperative pain, analgesia, and recovery-bedfellows that cannot be ignored. Pain 2018, 159 Suppl 1:S11-S16.

4. Kuzgunbay B, Turunc T, Akin S, Ergenoglu P, Aribogan A, Ozkardes H: Percutaneous nephrolithotomy under general versus combined spinal-epidural anesthesia. Journal of endourology 2009, 23(11):1835-1838.

5. Akinci G, Hatipoglu Z, Gulec E, Ozcengiz D: Effects of Ultrasound-Guided Thoracic Paravertebral Block on Postoperative Pain in Children Undergoing Percutaneous Nephrolithotomy. Turkish journal of anaesthesiology and reanimation 2019, 47(4):295-300.

6. Kim E, Kwon W, Oh S, Bang S: The Erector Spinae Plane Block for Postoperative Analgesia after Percutaneous Nephrolithotomy. Chinese medical journal 2018, 131(15):1877-1878.

7. Ozkan D, Akkaya T, Karakoyunlu N, Arik E, Ergil J, Koc Z, Gumus H, Ersoy H: Effect of ultrasoundguided intercostal nerve block on postoperative pain after percutaneous nephrolithotomy : prospective randomized controlled study. Der Anaesthesist 2013, 62(12):988-994.

8. Børglum J, Moriggl B, Jensen K, Lønnqvist PA, Christensen AF, Sauter A, Bendtsen TF: UltrasoundGuided Transmuscular Quadratus Lumborum Blockade. BJA: British Journal of Anaesthesia 2013, 111(eLetters).

9. Blanco R: 271: Tap block under ultrasound guidance: the description of a "no pops" technique. Regional Anesthesia and Pain Medicine 2007, 32(5):130-130.

10. Parikh GP, Shah VR, Vora KS, Parikh BK, Modi MP, Kumari P: Ultrasound guided peritubal infiltration of $0.25 \%$ Bupivacaine versus $0.25 \%$ Ropivacaine for postoperative pain relief after percutaneous 
nephrolithotomy: A prospective double blind randomized study. Indian J Anaesth 2014, 58(3):293297.

11. Blanco R, Ansari T, Girgis E: Quadratus lumborum block for postoperative pain after caesarean section: A randomised controlled trial. European journal of anaesthesiology 2015, 32(11):812-818.

12. Parikh G, Shah V, Vora K, Parikh B, Modi M, Panchal A: Ultrasound guided peritubal infiltration of $\mathbf{0 . 2 5}$ \% ropivacaine for postoperative pain relief in percutaneous nephrolithotomy. Middle East journal of anesthesiology 2013, 22:149-154.

13. Faul F, Erdfelder E, Buchner A, Lang AG: Statistical power analyses using G*Power 3.1: tests for correlation and regression analyses. Behavior research methods 2009, 41(4):1149-1160.

14. Jones P, Bennett G, Dosis A, Pietropaolo A, Geraghty R, Aboumarzouk O, Skolarikos A, Somani BK: Safety and Efficacy of Day-case Percutaneous Nephrolithotomy: A Systematic Review from European Society of Uro-technology. European urology focus 2019, 5(6):1127-1134.

15. Zhang $S$, Wu W, Huang Y, Wu W: Day-surgery percutaneous nephrolithotomy: a gap between inspiring results and the reality. World journal of urology 2020, 38(5):1347-1348.

16. Carney J, Finnerty O, Rauf J, Bergin D, Laffey JG, Mc Donnell JG: Studies on the spread of local anaesthetic solution in transversus abdominis plane blocks. Anaesthesia 2011, 66(11):1023-1030.

17. Sindwani G, Sahu S, Suri A, Saeed Z: Bilateral quadratus lumborum block for postoperative analgesia in a Von Hippel-Lindau syndrome patient undergoing laparoscopic radical nephrectomy. Saudi J Anaesth 2017, 11(4):513-514.

18. Haleblian GE, Sur RL, Albala DM, Preminger GM: Subcutaneous bupivacaine infiltration and postoperative pain perception after percutaneous nephrolithotomy. J Urol 2007, 178(3 Pt 1):925-928.

19. Tawfik MM, Mohamed YM, Elbadrawi RE, Abdelkhalek M, Mogahed MM, Ezz HM: Transversus Abdominis Plane Block Versus Wound Infiltration for Analgesia After Cesarean Delivery: A Randomized Controlled Trial. Anesthesia and analgesia 2017, 124(4):1291-1297.

20. Ahmet Murat Yayik1 AASODEOAHAA, Kursad2 H: Ultrasound-guided low thoracic paravertebral block versus peritubal infiltration for percutaneous nephrolithotomy: a prospective randomized study. Urolithiasis 2018.

21. Kilic E, Bulut E: Quadratus Lumborum Block III for Postoperative Pain After Percutaneous Nephrolithotomy. Turkish journal of anaesthesiology and reanimation 2018, 46(4):272-275.

22. Strichartz GR: Novel ideas of local anaesthetic actions on various ion channels to ameliorate postoperative pain. British journal of anaesthesia 2008, 101(1):45-47.

23. Yayik AM, Ahiskalioglu A, Demirdogen SO, Ahiskalioglu EO, Alici HA, Kursad H: Ultrasound-guided low thoracic paravertebral block versus peritubal infiltration for percutaneous nephrolithotomy: a prospective randomized study. Urolithiasis 2020, 48(3):235-244.

24. Bansal P, Saxena KN, Taneja B, Sareen B: A comparative randomized study of paravertebral block versus wound infiltration of bupivacaine in modified radical mastectomy. Journal of anaesthesiology, clinical pharmacology 2012, 28(1):76-80. 
25. Xu M, Tang Y, Wang J, Yang J: Quadratus lumborum block for postoperative analgesia after cesarean delivery: a systematic review and meta-analysis. International Journal of Obstetric Anesthesia 2020, 42:87-98.

26. Ueshima H, Otake H, Lin JA: Ultrasound-Guided Quadratus Lumborum Block: An Updated Review of Anatomy and Techniques. BioMed research international 2017, 2017:2752876.

27. Pietrow PK, Auge BK, Lallas CD, Santa-Cruz RW, Newman GE, Albala DM, Preminger GM: Pain after percutaneous nephrolithotomy: impact of nephrostomy tube size. Journal of endourology 2003, 17(6):411-414.

\section{Tables}

Table 1: Basic and operative characteristics

\begin{tabular}{|c|c|c|c|c|c|}
\hline \multirow[b]{2}{*}{ Age (years) } & \multicolumn{2}{|c|}{$\begin{array}{l}\text { Peritubal } \\
(\mathrm{N}=29)\end{array}$} & \multicolumn{2}{|c|}{$\begin{array}{l}\text { Quadratus } \\
(\mathrm{N}=29)\end{array}$} & \multirow{2}{*}{$\begin{array}{l}\text { P-value } \\
325^{\#}\end{array}$} \\
\hline & 46.8 & 7.1 & 44.9 & 7.7 & \\
\hline \multicolumn{6}{|l|}{ Sex } \\
\hline Female & 16 & $55.2 \%$ & 16 & $55.2 \%$ & \multirow[t]{2}{*}{$1.000^{\# \#}$} \\
\hline Male & 13 & $44.8 \%$ & 13 & $44.8 \%$ & \\
\hline Height (cm) & 1.7 & 0.05 & 1.7 & 0.03 & $0.695^{\#}$ \\
\hline weight (kg) & 79.4 & 10.7 & 75.9 & 10.8 & $0.221^{\#}$ \\
\hline Body mass index $(\mathrm{Kg} / \mathrm{m} 2)$ & 28.3 & 3.8 & 27.1 & 3.7 & $0.253^{\#}$ \\
\hline Duration of surgery (min) & 73.2 & 10.9 & 72 & 11.2 & $0.670^{\#}$ \\
\hline \multicolumn{6}{|l|}{ Side } \\
\hline LT & 14 & $48.3 \%$ & 15 & $51.7 \%$ & \multirow[t]{2}{*}{$0.793^{\# \#}$} \\
\hline RT & 15 & $51.7 \%$ & 14 & $48.3 \%$ & \\
\hline Stone size $(\mathrm{mm})$ & 38.3 & 5.7 & 39 & 3.5 & $0.598^{\#}$ \\
\hline
\end{tabular}

\#Independent-t test \#\#Chi-squared test

Table 2: Postoperative morphine consumption 


\begin{tabular}{|c|c|c|c|c|c|c|}
\hline \multirow[b]{2}{*}{$\begin{array}{l}24 \text { hour morphine } \\
\text { consumption in mg }\end{array}$} & \multicolumn{2}{|c|}{$\begin{array}{l}\text { Peritubal } \\
(\mathrm{N}=29)\end{array}$} & \multicolumn{2}{|c|}{$\begin{array}{l}\text { Quadratus } \\
(\mathrm{N}=29)\end{array}$} & \multirow{2}{*}{$\begin{array}{l}\text { P-value } \\
<0.0001 \text { *\# }\end{array}$} & \multirow{2}{*}{$\begin{array}{l}\text { Estimate of } \\
\text { Treatment effect } \\
9(7-10)\end{array}$} \\
\hline & 18 & $\begin{array}{l}(17- \\
20)\end{array}$ & 9 & $(8-11)$ & & \\
\hline First PCA use time in minute & 66.6 & 2.3 & 72.1 & 3.9 & $<0.0001$ *\#\# & $\begin{array}{l}-5.586(-7.257 \text { to } \\
-3.916)\end{array}$ \\
\hline
\end{tabular}

\#Mann-Whitney U test, treatment estimate represents median difference and 95\% confidence interval \#\#Independent-t test, Treatment estimate represents mean difference and 95\% confidence interval *Significant

Table 3: Postoperative outcome

\begin{tabular}{|c|c|c|c|c|c|c|}
\hline & \multicolumn{2}{|c|}{$\begin{array}{l}\text { Peritubal } \\
(\mathrm{N}=29)\end{array}$} & \multicolumn{2}{|c|}{$\begin{array}{l}\text { Quadratus } \\
(\mathrm{N}=29)\end{array}$} & P-value & $\begin{array}{l}\text { Estimate of Treatment } \\
\text { effect }\end{array}$ \\
\hline \multicolumn{7}{|c|}{ Nausea and vomiting } \\
\hline Y & 9 & $31.0 \%$ & 5 & $17.2 \%$ & \multirow{2}{*}{$0.220^{\# \# \#}$} & \multirow[t]{2}{*}{$1.800(0.686-4.722)$} \\
\hline$N$ & 20 & $69.0 \%$ & 24 & $82.8 \%$ & & \\
\hline \multicolumn{7}{|l|}{ pruritus } \\
\hline Y & 6 & $20.7 \%$ & 4 & $13.8 \%$ & \multirow[t]{2}{*}{$0.487^{\# \# \#}$} & \multirow[t]{2}{*}{$1.500(0.472-4.764)$} \\
\hline$N$ & 23 & $79.3 \%$ & 25 & $86.2 \%$ & & \\
\hline $\begin{array}{l}\text { Patient } \\
\text { satisfaction }\end{array}$ & 3 & $(2-4)$ & 4 & $(3-4)$ & $0.006^{* \#}$ & $-1(-1$ to 0$)$ \\
\hline
\end{tabular}

\#Mann-Whitney U test, treatment estimate represents median difference and 95\% confidence interval \#\#\#Chi-squared test, Treatment estimate represents relative risk

*Significant

\section{Figures}




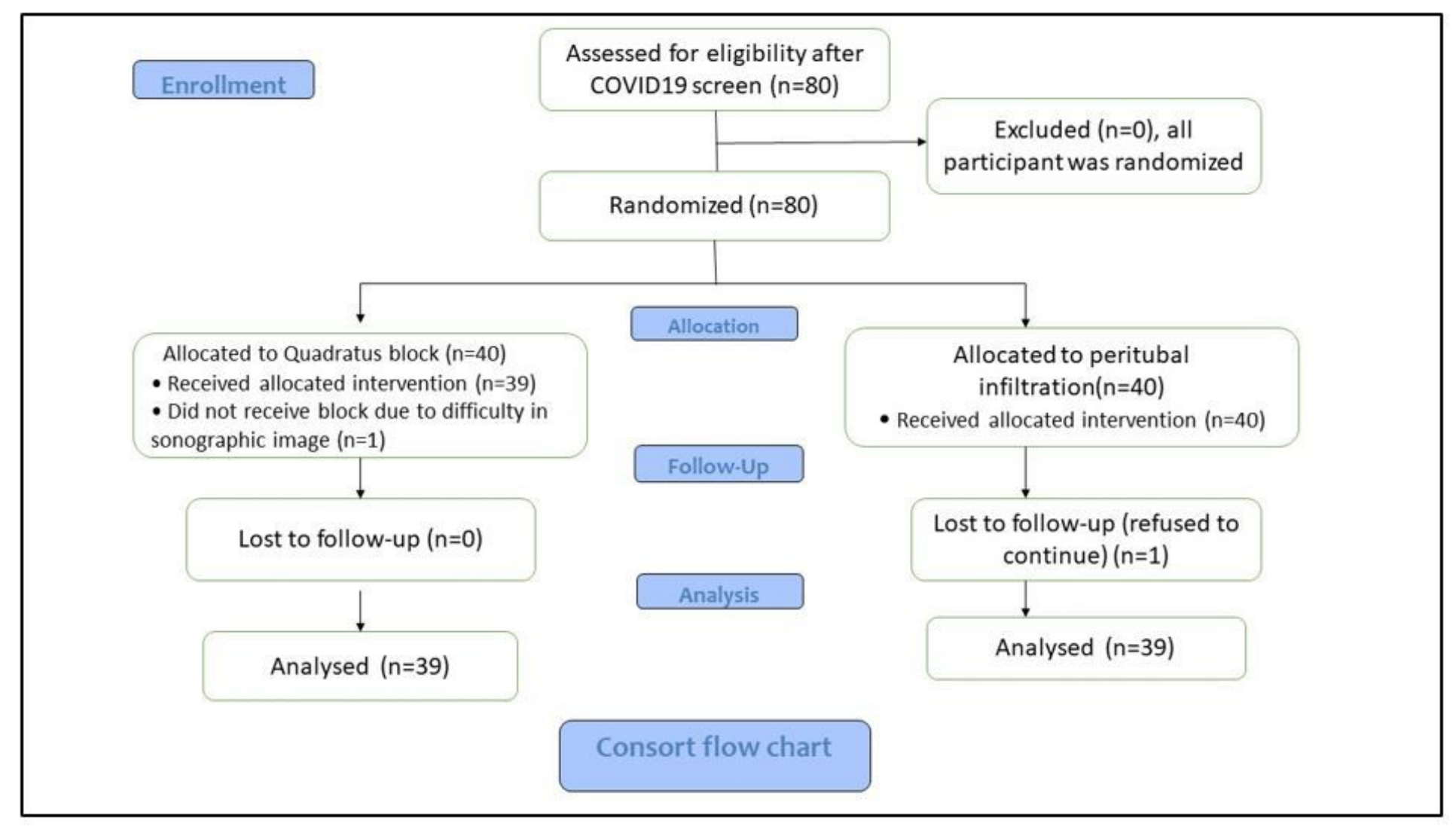

Figure 1

Consort flow chart 


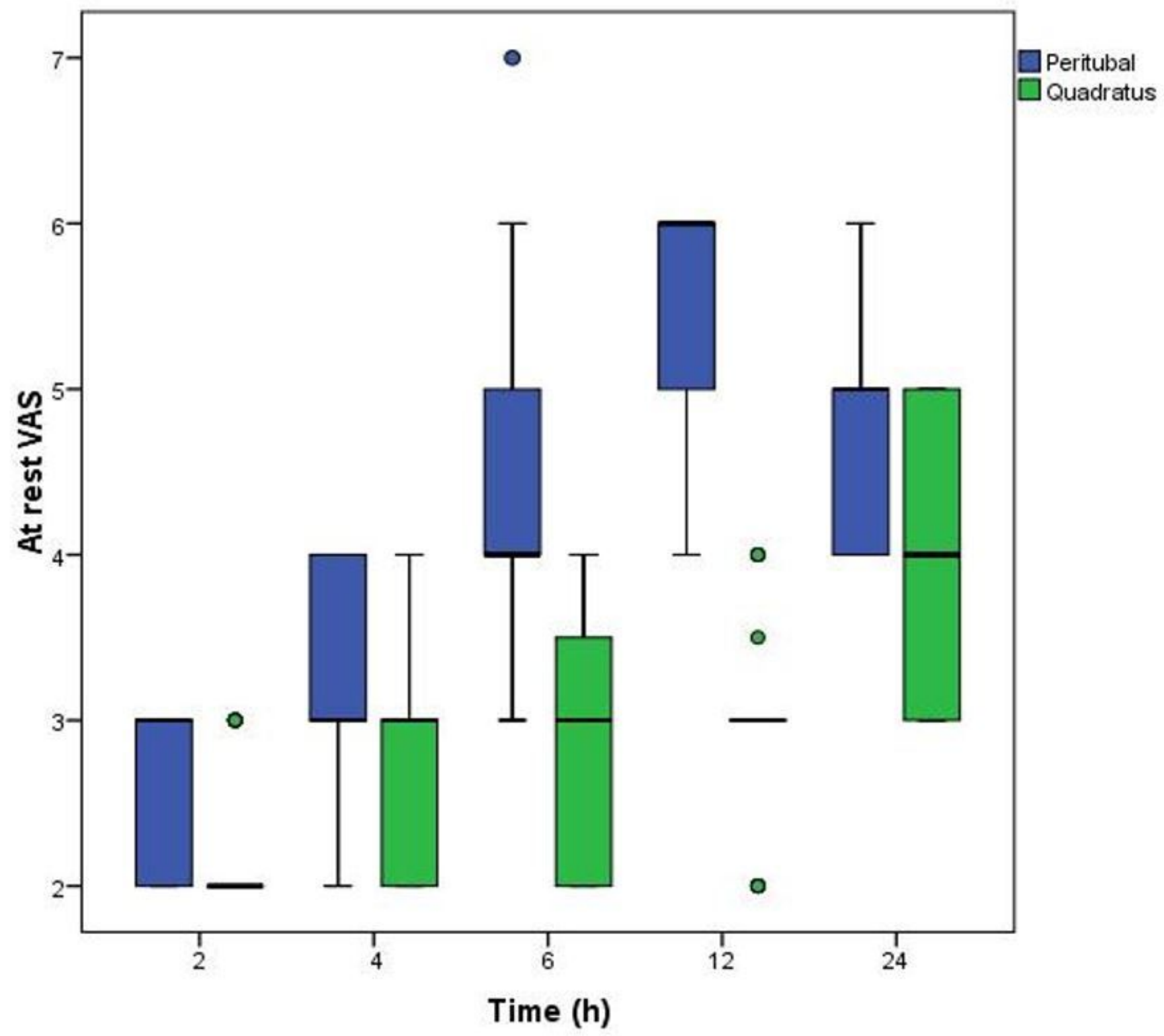

Figure 2

Box plots of pain scores at rest assessed using an 11-point numerical rating scale $(0=$ no pain and $10=$ the worst possible pain) over time after cesarean delivery. Significantly lower in group $Q$ at 12 hours. 


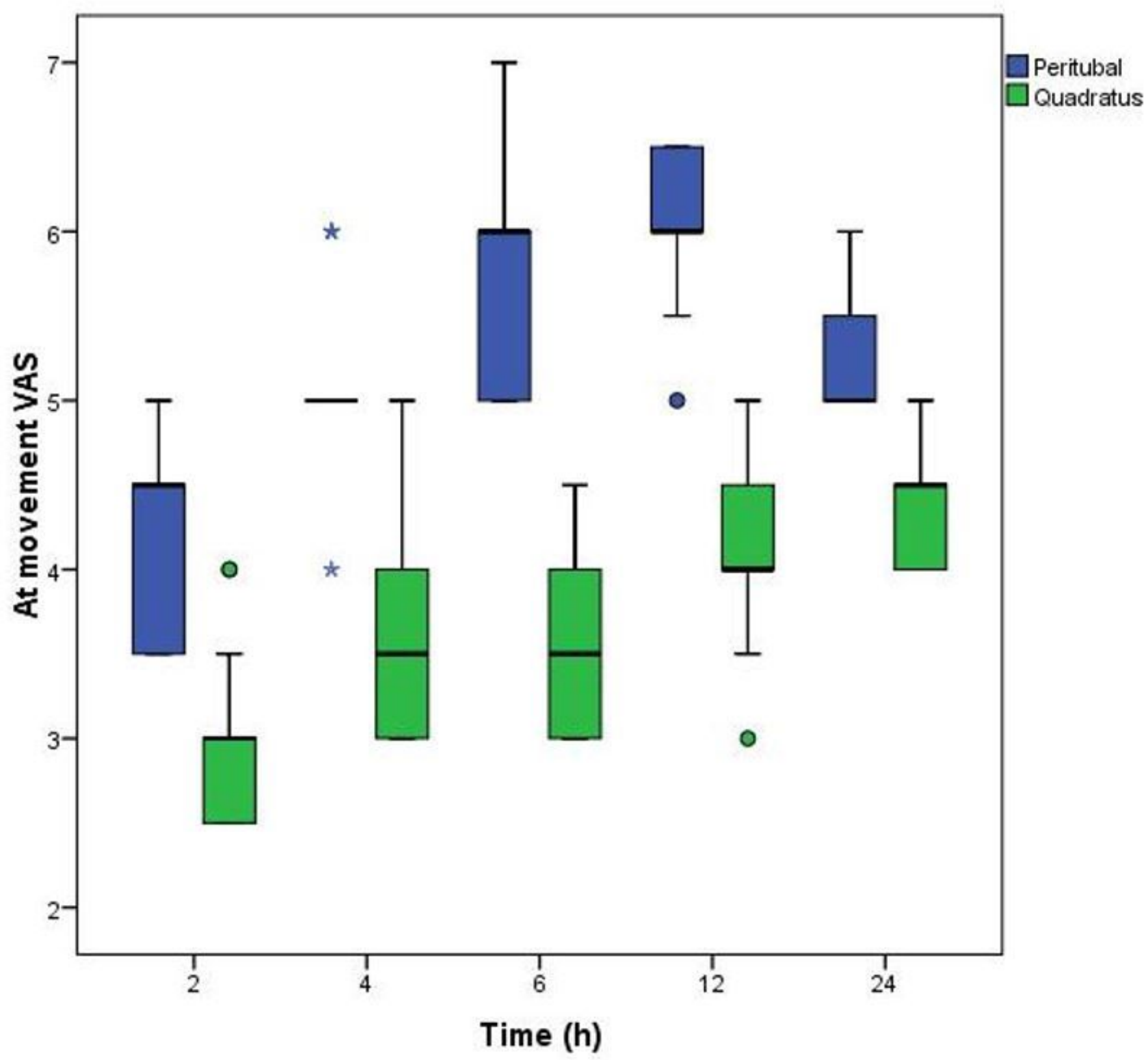

Figure 3

Box plots of pain scores on movement assessed using an 11-point numerical rating scale $(0=$ no pain and $10=$ the worst possible pain) over time after PCNL. The dynamic VAS score was significantly higher among patients in peritubal group 


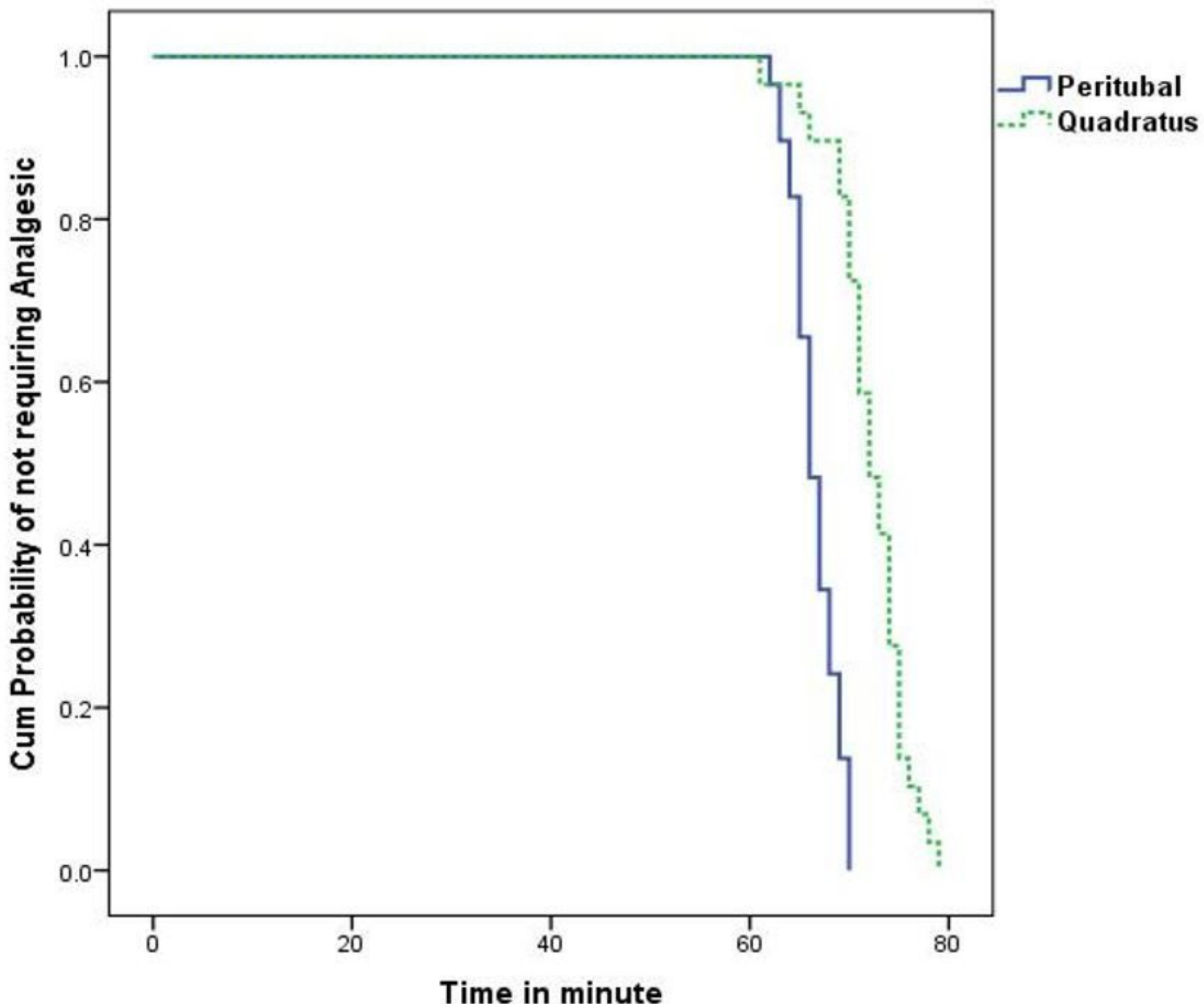

Figure 4

The time for the first analgesic request was significantly shorter in the peritubal group than in the quadratus group, as described by the Kaplan Meier method, $p<0.0001$.

\section{Supplementary Files}

This is a list of supplementary files associated with this preprint. Click to download.

- CONSORTChecklist.doc 